\title{
Conference Report: Experience as a Research Method in Performing Arts. Where does conference style make strides?
}

\author{
Kateřina Šalounová
}

9th International Conference of Doctoral Studies in Theatre Practice and Theory. Hosted by The Theatre Faculty of the Janáček Academy of Music and Performing Arts in Brno. 22-23 November 2019.

The Theatre Faculty of the Janáček Academy of Music and Performing Arts in Brno has been organising international doctoral conferences since 2003. The founders of the tradition were Professor Josef Kovalčuk, Professor Petr Oslzlý, and Professor Pentii Paavolainen of Helsinki Theatre Academy. The conference was originally established as a discussion forum for the doctoral students of various theatre schools and has continued the tradition of being a discussion forum for the open-minded ever since. Since 2015, the Conference has been embracing interdisciplinary approaches to the study of dramaturgy with the emphasis on problem-oriented papers. The topic of 2015 Conference was Artistic Research, and in 2017 it was dedicated to Political Issues. In 2019, the Conference organizers focused on the experience as a research method employed in the Performing Arts. Traditionally, the speakers came from the Czech and Slovak Republics, as well as from Germany, Finland, Romania, Greece, Sweden, Poland and the Philippines. An interesting highlight of the 2019 Conference was the experimenting with the forms of the papers and the ways of their presentation to the audience, obviously stipulated by the topic of discussion.
The program of the two-day conference consisted of six sessions. The session 'Challenges of Radio Studies' included papers by Iveta Novotná 'Work with the Principles of Radio Journalism in Radio Drama' and Tereza Reková 'LET'S GET TOGETHER! The importance of Not Getting Stuck in Your Own Bubble'. Both of the speakers are $\mathrm{PhD}$ students at the Theatre Faculty of the Janáček Academy of Music and Performing Arts in Brno. Novotná dealt with radio pieces created by way of combining the principles of radio journalism and radio drama. She described six categories of these radio pieces: from imitation of radio broadcast through documentary radio play and fictional documentary confession to a 'pásmo' play oscillating between an artistic intervention and actual journalism. Reková spoke of her cooperation with an American producer Dennis Funk on the first USA-Czech docu-radio drama. The documentary deals with the specific features and dissimilarities of the radio production in different countries and captures how those countries make use of the basic tools of documentary-making in artistic creation. Reková's view of international cooperation was based on her interviews with specialists in the field, overview of literature, and personal experience. She 
concludes that cultural, linguistic, and, in her particular case, generational difference, cannot and should not become stopping blocks for a productive cooperation.

The second session was devoted to exploring the limits of the body. Cosmin Matei from the Theatre and Film $\mathrm{PhD}$ School, Babeş-Bolyai University in Romania presented on 'Hearth Athlete's Corporeal - An Innovative Research Method and Its Limitations', and Laura Brechmann, a doctoral student at Johannes-Gutenberg University in Mainz, Germany, at the Film-Theater-Media- and Cultural Anthropology Institute gave a talk entitled 'Repeating. The Dizziness'. The two diametrically different approaches to the presentation of the findings revealed their weak as well as the strong points. For instance, Matei strived to present the research methodology of his doctoral thesis in a highly analytical way, assessing the systems of bio-psycho-physiological dynamics used in the contemporary actors training. Regrettably, his presentation overwhelmed with terminology and details turned out to be challenging for comprehension. On the other hand, in Brechmann's discussion of how dizziness could function as a choreographic element in dance the lively and captivating form somewhat surpassed its content.

The session that concluded the first day of the conference was dedicated to the search for new methodologies in artistic research. Miloslav Juráni from the Theatre Faculty of the Academy of Performing Arts in Bratislava in his talk entitled "How to Research Toward "Green": art $\rightarrow$ nature $\leftarrow$ theory' contemplated on the methods of theatre research which might help the researcher with analysing performances dealing with the environmental topics. Juráni was in particular concerned with the question of how application of the existing eco-approaches could help to understand drama, performance, or a performative event, and how to find new ways for contemporary theatre to cope with the growing interest of both politicians and general public in the environment and global warming. One of Juráni's conclusions was that a piece of art has the greatest power when the viewer is not aware of the fact that what they are watching is actually supposed to be art.

Alžběta Vaculčiaková, a PhD student at the Janáček Academy of Music and Performing Arts in Brno, demonstrated in her paper 'The True of Self-expression' with the help of simple exercises how to feel free in a creative process. She has been mentoring three actors, teaching them how to feel free in their self-expression first via scrutinizing a room intuitively and then repeating their movements and actions again - that is actually performing and feeling authentic at the same time. Vaculčiaková, thus, pointed out to the distinction between 'existing' and 'performing', stressed the importance of the technique of movement and a link between movement and empathy. For a deeper comprehension Vaculčiaková communicated with the audience during the presentation-performance, asking them to sit comfortably and massage their ears. The speaker also invited the audience to open up to the creative potentials and enliven their bodies through what she called 'the memory of the past generations'.

The last presenters in this block were Taneli Tuovinen and Riku Saastamoinen of the Theatre Academy, University of the Arts in Helsinki. These two artists and teachers from Finland conjointly presented a paper 'Artistic Research as a Pos- 
sibility to Ask Better Questions in Art Pedagogy' about artistic research as a possibility to ask better questions in the art pedagogy. In the simple terms the trust is their method - the belief in the process of specific exercises.

The second day of the Conference was dedicated to three central issues in the performing arts: 'experience, research, authenticity'. The topic of authenticity was reflected in Otto Kauppinen's, the Janáček Academy of Music and Performing Arts in Brno, Joanna Kocemba-Żebrowska's, the Institute of Art of Polish Academy of Science in Warsaw, and Feliz Anne Reyes Macahis', Universität für Musik und darstellende Kunst Graz, talks. Of the three scholars, Kauppinen, who studies socially engaged theatre, asked in his presentation 'Cadavers of Authenticity in Artificial Hells. Researching the Relational and Participatory Aspects of a Performance' questions about the participatory aspects of performance, about the lecturer's or researcher's confrontation with their own authenticity and he also suggested some hermeneutic tools which could be applied to a mediated performance. To illustrate his points, Kauppinen used a fragment of a filmed performance about a new species called Agronaut which had been observed by the original audience through spectators' mobile phones. Kauppinen pointed out that the spectacularity has replaced performativity in this particular case. Throughout his presentation, he oscillated at his own performative level between the role of a performer and a speaker, balancing the scientific-objective approach with artistic-subjective one.

The keynote speaker of the next session was Dr. Johana Kotišová, an Associate Professor at the Department of Media Stud- ies and Journalism at the Faculty of Social Studies, Masaryk University, Brno. She related the topic of the previous session to the theme of exploring and expressing. The papers 'Practical Research in Action Voice as a Laboratory' by Anna Čonková, a doctoral student at the Janáček Academy of Music and Performing Arts in Brno, 'Unknown as a Research Method in Performing Arts' by Eva Priečková, a contemporary Slovak dancer, choreographer, performer, theorist, and teacher, and 'Savage Mind in Theatre' by Erik Alalooga, a doctoral student at the Estonian Music and Theatre Academy, contributed to the discussion of the issue. Kotišová in her talk 'Creative Methodologies: Towards More Engaging and Engaged Research' stressed the potential of combining art and science using the example of her dissertation which she wrote in a form of a novel and later published with a prestigious academic publisher. She also discussed the ethical implications of this approach, suggesting that writing about social science in the style of a creative nonfiction can help produce more engaged texts which imply complex meanings and grasp diversified points of views. While being able to organize data into meaningful discourses, such texts are accessible to more people, in the end having greater impact than a standard scholarly work. Kotišová also emphasized the responsibility of a scholar to communities arising from the public financing of research.

The last session entitled 'Disability and Performance' closed the conference with a discussion of socials aspects of theatre-making. The papers 'Disability and Performance: How the "En Dynamei Ensemble" Challenges the Boundaries of Traditional Aesthetic Practices' by Kyriaki 
Diversity.

Passion. Crossing the borders.

Artohilic.
Overartisted.
Community.
Objectivity.

Self-reflexion. Searching the form.

Artistic value.

The translation of performance to the words.

Borders between science and art.

Create an experience.

Searching inside and outside.

Correlation.

Fig. 1: ,Associations of collective brainstorming'

Demiri, a post-doc researcher at the Aristotle University of Thessaloniki, 'Theatre Experiment in Czech Sign Language: Life Sentence - The Worst Will Stay' by Radka Kulichová from the Janáček Academy of Music and Performing Arts in Brno and 'Artistic Interpreting of Music into Czech Sign Platform' by Daniela Cincibus Vacková from the Janáček Academy of Music and Performing Arts in Brno contributed to the debate. Demiri presented the En Dynamei Ensemble, a theatre group in which disabled and non-disabled artists work together not to create performance 'about' disabled bodies but to 'stage' these bodies in and via the performance. As the performances of the Ensemble make the audience stare at the disabled bodies, they manage to push the viewers out of their comfort zone, inviting them to re-evaluate the boundaries of theatre itself. Kulichová and Cincibus Vacková both addressed the topic of the sign language and its use in theatre performances. They emphasized the benefits of such practice for better social inclusion of people with hearing im- pairment. At the same time, they stressed that sign language as a tool of communication and as a performative element is actually an aesthetic category.

The concluding discussion panel took place at the large hall of the Theatre Faculty of the Janáček Academy of Music and Performing Arts in Brno. The speakersperformers, audience, and organizers were seated around a large round table: such arrangement offered a great opportunity to share the views and experiences of the conference as well as opinions on particular topics. The round table was moderated by David Drozd, the Head of the Department of Theatre Studies at Masaryk University, Brno, who opened the session with a collective brainstorming. The participants worked out a set of associations that were proclaimed as the key words of the conference, (see Fig. 1).

It became clear during the discussion that the necessity to adhere to the academic rules is an issue of debate for the doctoral students in both the Arts and Humanities. The Humanities are, by and large, aimed 
at investigating the very general and fundamental questions of knowledge, reality, mind, morality, logic, language, reasoning, politics, value, etc., and the Arts help to translate or transfer the ideas through emotions, such as passion and fascination. While sometimes seen as exclusive of each other, the Arts and Humanities can actually profit of their synthesis.

Another point in the discussion was that the position of a scholar implies, on one hand, an objective detachment from the object of inquiry, while the position of an artist, a necessarily subjective approach to it. We are unique as artists or scientists; our points of view are different when we actually present ourselves. During the conference, it became clear that many PhD students in the Arts and Humanities experience some sort of discrepancy between the objective scholarly frame of their research and its artistic content based on their individual creative capacities. The academic hierarchies and somewhat rigid, highly formalized style of academic writing, thus, place considerable intellectual demands on the PhD students as authors. For example, there is the responsibility to decide which sources to quote and which not, what is principal in relation to a particular argument and what can be left out, etc. While being generally a good thing for the development of the academic debate, these rules at the same time exert pressure on a $\mathrm{PhD}$ candidate, who needs to do a lot of reading and thinking to get herself/himself oriented in the previous argumentation concerning their object of study and build on it in a sensible way to achieve meaningful results of research.

It follows that the academic style may seem at times dull and boring, hence inappropriate to deal with such passing and elusive phenomenon as art, and theatre/ performance in particular, is. Especially in live presentation at conferences, inconvenient distance often raises between the speaker and the audience. One of the important conclusions of the conference thus was that the artistic way of formulating ideas can sometimes be more suitable for thinking and speaking about the art than the strictly objective/scholarly discursive mode. No doubt, art studies are still required to reflect social, philosophical, political and other contexts of a piece of art: but the academic style needs to be slightly transformed when discussing art as its subject matter. This is the challenge for PhD students to apply their creativity, passion and also critical thinking or ethical codex of research.

In my opinion, it became apparent during the conference how important the dramaturgical feeling of the speakers and their experience with presenting for public is with regard to the success of their presentations. Naturally, their individual backgrounds (academic, practical, or mixture of both) play an important part in the dramaturgy of the individual speakers' presentations and the actual form they chose for presenting their papers. This edition of the conference suggested that we are witnessing a considerable accommodation of content and form in presentation of the Artistic Research. For the time being, it is not yet a fusion, nor a perfectly dramaturgically captured synthesis, but this process can be definitely seen as productive and worth pursuing further.

An ideal symbiosis between the intellectual and intuitive approach to art research was traced during the performance of Eva Priečková. She gained her Master's degree at the Dance Department of the Academy 
of Performing Arts in Bratislava and her thesis focused on the relation of voice and motion in dance improvisation. As a form of her lecture performance at the conference she chose her solo performance about embodying dance from 2017. In her talk-performance 'Unknown Concept', she was using the perception through unknown as a research method in the Arts. An artistic-scholarly experiment, a step outside of our routine habits as students, scholars and professionals, Priečková's performance communicated primarily via verbal explanation only to expand its mediality towards a nonverbal journey through an accelerating and slowing movement reflecting the dynamics of utterances. Surprisingly, her physical expression and physical engagement did not weaken her voice, on the contrary she mastered her breathing technique and opened herself to sensitivity in searching for the optimal way of presentation 'Unknown is the excuse to dance'. Trying to find a hidden knowledge could happen through pure physicality of Priečková's performance, simple dance moves and the performer's ability to shift away from the usual self.

To sum up the outcomes of the conference, one of the major findings for me was the fact that producing knowledge means also producing the contexts and discourses about this knowledge. It is necessary in the Artistic Research to go through the processes of thinking, researching, performing and so on again and again, re-interpreting and reinventing issues once they appear as relevant on the epistemic horizon. Personal involvement - as probably in all fields of human endeavours - seems to be the best motivation to document and construe any issue for further generations, in a performative way or another. 